\title{
CONSIDERATIONS ON APPLYING PRACTICAL CONTROL METHODS IN THE BIOLOGICAL TREATMENT OF WASTEWATERS FROM PAPER MANUFACTURING
}

\author{
Petronela NECHITA ${ }^{1}$, Carmen Mariana BURTEA ${ }^{1}$, \\ Vasilica BARBU ${ }^{2}$ \\ ${ }^{1}$ Department of Environmental, Applied Engineering and Agriculture, \\ "Dunarea de Jos" University of Galati, Romania \\ ${ }^{2}$ Department of Food Science and Engineering and Applied Biotechnology, \\ "Dunarea de Jos" University of Galati, Romania \\ e-mail: Petronela.Nechita@ugal.ro
}

\begin{abstract}
Due to high efficiency, in terms of effluent quality, the activated sludge treatment is the most common method for removing the biodegradable impurities from industrial and urban wastewaters. Although these engineering systems of biological wastewater treatments increase the rate of biodegradable substances removing, in most cases, these are rarely able to achieve the maximum performances due to the lack of some fast methods to monitor and control the living biomass. In this context, in present paper are described some methods for evaluation of viability and biological activity of activated sludge, as essential parameters for ensuring the performance of biological treatment process. The proposed methods are based on the determination of metabolically active bacteria in activated sludge, using the activity of dehydrogenase enzymes (Triphenyl tetrazolium chloride TTC method) in the biological treatment of wastewaters generated from the paper manufacturing process.
\end{abstract}

KEYWORDS: activated sludge, bacterial respiration, biomass living, triphenyl-formazan, wastewater treatments, recovered papers

\section{Introduction}

The pulp and paper industry are ranked as large consumers of water and are consequently producing high amounts of wastewaters [1]. The environmental impact of pulp and paper industry is a particular concern since it generates large quantities of effluent with a high pollution loading, being considered a sixth largest polluter in the world (after oil, cement, leather, textile, and steel industries), eliminating a variety of gaseous, liquid, and solid wastes to the surroundings [2, 3].

Generally, pulp and paper industrial effluent is rich in recalcitrant compounds that cause severe pollution. For the treatment of such compounds, activated sludge process is frequently used to reduce the biodegradable organic pollutants from these wastewaters [4]. Practically, the process consists in treating of wastewater loaded with high content of organic impurities with a mass of microorganisms (activated sludge) in the presence of oxygen and controlled temperature, $\mathrm{pH}$ or the inhibitors content. The wastewater pollutants are mineralised to $\mathrm{CO}_{2}$ and $\mathrm{H}_{2} \mathrm{O}$.

$$
\begin{gathered}
\mathbf{C}_{\mathbf{x}} \mathbf{H}_{\mathbf{y}}+\mathbf{O}_{2}+m / n=\mathbf{H}_{2} \mathrm{O}+\mathbf{C O}_{\mathbf{2}}+\text { biomass } \\
(m-\text { microorganisms, } n-\text { nutrients })
\end{gathered}
$$

The activated sludge consists of a complex biological community including viruses, bacteria, protozoa fungi and metazoa that achieve the degradation of organics in waste water $[5,6]$. Quantitatively, bacteria represent around 95\% (approx. 108 - 1010 microorganisms/l) of the total microbial population and are essential for biological removal of organic carbon, ammonium and phosphate in the aeration tank.

The activated sludge technology is based on the ability of microorganisms to form flocs when wastewater is aerated. Within flocs, living and dead cells, organic and inorganic particles, fibres are held together by a slime matrix produced by bacteria. 
Optimal formation of flocs is essential for sludge quality and clean water leaving the final clarifier.

\subsection{Methods for control of activated sludge viability and activity}

Determination of microbial activity is of high importance for process analysis in biological wastewater because the degradation of organic matter, system productivity, and biomass turnover all depend on metabolically active microorganisms [7]. Control tests for monitoring the wastewater treatment plants are performed aiming to respect the regulation regarding wastewater effluents. The activity of bacteria in activated sludge is usually evaluated by measuring general parameters such as rate of oxygen uptake, adenosine triphosphate (ATP) content, biomass, or substrate utilisation. Other physicalchemical parameters are Mixed Liquor Suspended Solids (MLSS) that is a measure of total solids contained in the bioreactor, and the Mixed Liquor Volatile Suspended Solids (MLVSS), measuring the total microorganisms' compound, regardless to the fact if it is dead or alive. These parameters do not provide any information about the distribution of microbial activity or viability in sludge populations [7].

As of yet it is not known which bacteria in activated sludge are metabolically active and what constitutes their impact on system performance. However, only living and active biomass is important for degrading organic pollution and there is a lack today of operational tools allowing direct measurement of active biomass in the bioreactors [8].

Bacterial counts (aerobic mesophilic bacteria$\mathrm{AMB}$ ) can be determined using various techniques such as plate counting turbidity measurement, microscope enumeration and dehydrogenase activity measurement, but the procedure is time consuming and considerably underestimates the number of viable bacteria cells in activated sludge.

The standard parameter of the biomass that forms the activated sludge is the volatile part of the suspended matter called volatile suspensions. The active volatile biomass fraction depends on the organic fraction of the raw wastewater and the activated sludge age (as the sludge is the older the higher quantity of intra- and extracellular, inert and hardly degradable polymers is presented). The biodegradable fraction (about 77\%) can be a parameter of the biological activity of the activated sludge. It represents the difference between initial volatile suspensions of an activated sludge taken from the WWTP and volatile slurries of the same sludge after an extended aeration period (about 30 days when the degradation no longer occurs) related to the initial volatile feedstock.
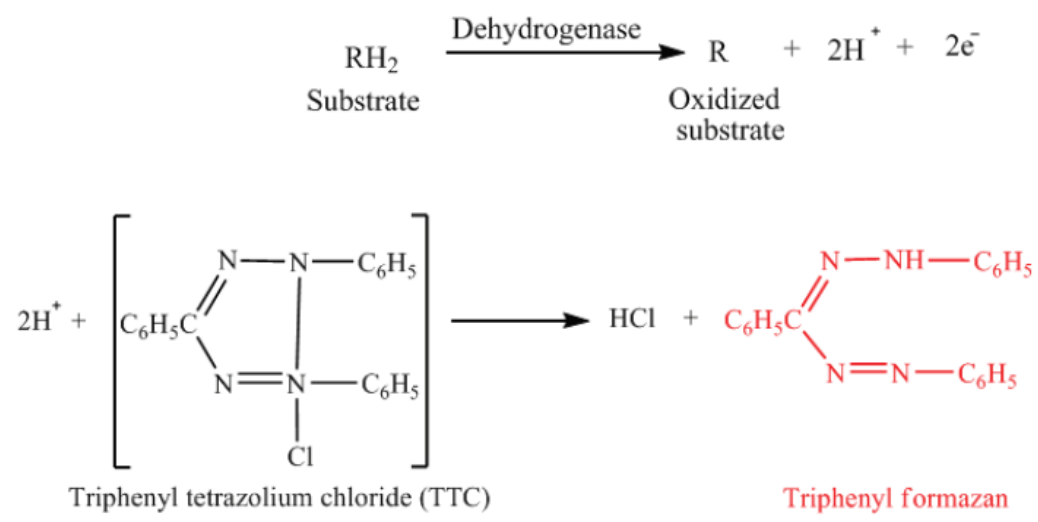

Fig. 1. Mechanism showing the role of dehydrogenase in the reduction of triphenyl tetrazolium chloride (TTC) to triphenyl formazan (TF) [10]

The dehydrogenase activity measurement technique has the advantage over other methods in being able to quantify the number of live cells that are present in the medium and it can be used in a relatively short time as well as at a low cost [9]. The dehydrogenase activity test is based on the principle that dehydrogenase enzymes are produced by all living cells and the extent to which this enzyme group oxidizes organic matter can be related to the number of live cells present. This group of enzymes transports electrons and hydrogen through a chain of intermediate electron carriers to a final electron acceptor (oxygen), resulting in the formation of water. The activity of the co-enzymes Nicotinamide Adenine Dinucleotide (NAD) and Flavin Adenine Dinucleotide (FAD) which act as intermediate electron acceptors can be measured by the visible colour change of a dye such as triphenyl tetrazolium 
chloride (TTC). The process of measuring of dehydrogenase activity involves incubating the sample in the presence of triphenyl tetrazolium chloride and an electron-donating substrate. In its oxidized form, TTC is colourless, but in the presence of dehydrogenase enzymes, TTC is reduced to triphenyl formazan (TF), a red water insoluble compound [10]. The TF is retained within microbial cells and can result in highly coloured colonies when grown on agar plates [11]. The mechanism of the process is summarized in Figure 1. Triphenyl formazan (TF) can be extracted from cells using a solvent and the concentration is determined using colorimetry method by measuring the absorbance at 450-484 nm [10]. However, the amount of TF extracted depends on number of extractions, extraction solvent, incubation time and temperature, and medium $\mathrm{pH}$.

The main objective of our study was to develop and to verify a dehydrogenase activity test to quantify the live bacterial cells from the mixed liquor suspended solids of aeration reactor from recycled paper wastewater treatment plant. Some correlations between the obtained results with this method and physical-chemical parameters of activated sludge from aeration tank, have been completed.

\section{Experimental}

\subsection{Materials}

The triphenyl tetrazolium chloride (TTC), as solution with $1 \%$ concentration was used for the dehydrogenase test. The triphenyl formazan (TF) was extracted from the microorganisms' cells using ethylic alcohol (96\% purity). The activated sludge was collected from aeration reactors of biological treatment plant of wastewaters generated from recycled papers processing. The study was based on instant collected samples for a period of 5 days.

\subsection{Methods}

Dehydrogenase activity: $4.3 \mathrm{~mL}$ of activated sludge (diluted with distilled water until its total solids content is about $1 \mathrm{~g} / \mathrm{L}$ ) was removed into test tubes and mixed with $0.5 \mathrm{~mL}$ TTC, solution $1 \%$. The test tubes were gently swirled to mix the content and then incubated at $20-25^{\circ} \mathrm{C}$ for $30 \mathrm{~min}-2$ hours until the red colour appears. After this, the tubes were centrifuged for 3-10 min to separate the cells from other medium components. The resulted supernatant was discarding. The water-insoluble formazan extracted with ethanol was measured with a photometer. Thus, TF extraction was carried out three times using $5 \mathrm{~mL}$ ethanol each time. All the filtrates were combined and the absorbance of each solution was measured using a spectrophotometer at a wavelength of 450-484 nm (Figure 2).

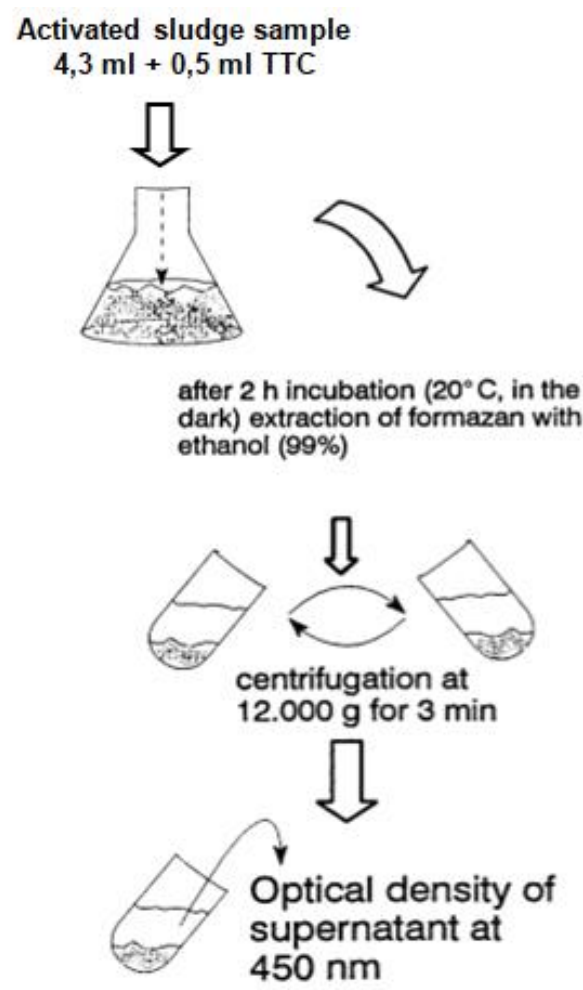

Fig. 2. Flow diagram of the dehydrogenase activity assay in activated sludge

The absorbance readings were used to calculate the activated sludge activity (As) as follow:

$\mathbf{A s}=\mathbf{C}_{1} / \mathbf{C}_{2}=\mu \mathrm{g}$ formazan $/ \mathrm{mg}$ sludge total solids (1)

where:

$\mathrm{C} 1=$ measurement result (concentration of formazan $(\mu \mathrm{g}))$

$\mathrm{C} 2=$ concentration of activated sludge $(\mathrm{mg})$ :

$$
\mathrm{C}_{2}=\mathrm{V} \times \mathrm{TS}
$$

where:

$\mathrm{V}=$ volume of activated sludge $(\mathrm{mL}), \mathrm{TS}=$ total solids content in MLSS ( $\mathrm{g} / \mathrm{L})$

As $=$ activity of the sludge expressed in $\mu \mathrm{g}$ formazan, represented by $1 \mathrm{mg}$ sludge total solids.

Mixed Liquor Suspended Solids (MLSS) contained in the mixed liquor from aeration reactor was determined by drying at $105{ }^{\circ} \mathrm{C}$. The test is essentially the same as the test performed for TSS in the wastewaters, except for the use of mixed liquor (activated sludge and wastewater) as sample. In 
addition, the concentration of suspended solids found in the mixed liquor is typically much greater than that found in the wastewater.

Mixed Liquor Volatile Suspended Solids (MLVSS), is a test for volatile suspended solids (organic amount) found in a sample of mixed liquor. Volatile solids are those solids which are burnt up when a sample is heated to $550{ }^{\circ} \mathrm{C}$. Most of the volatile solids in a sample of mixed liquor will consist of microorganisms and organic matter. As a result, the volatile solids concentration of mixed liquor is approximately equal to the amount of microorganisms in the water and can be used to determine whether there are enough microorganisms present to digest the sludge. The normal range of volatile portion in a mixed liquor sample is usually between $60-80 \%$ from total suspended solids.

Aerobic mesophilic bacteria (AMB) determined as plate (Plate Count Agar) counting of aerobic mesophilic bacteria in the suspension volume unit.

Sludge volumetric index (SVI) as ratio between the volume of sedimentary activated sludge for 30 minutes expressed in $\mathrm{ml} / \mathrm{l}$ of slurry and the amount of dry matter expressed in g dry weight/L of slurry).

\section{Results and discussions}

The results obtained of each parameter during the study period are shown in Table 1 .

Table 1. The physical-chemical parameters of activated sludge from aeration tank

\begin{tabular}{|c|c|c|c|c|c|c|c|}
\hline Sample & $\begin{array}{c}\text { MLSS } \\
\mathrm{mg} / \mathrm{L}\end{array}$ & MLVS, $\%$ & $\begin{array}{c}\text { As } \\
\mu \mathrm{g} \\
\text { formazan/mg } \\
\text { MLSS }\end{array}$ & $\mathbf{S V I}$ & $\begin{array}{c}\text { AMB, } \\
\text { ufc/g }\end{array}$ & T, ${ }^{\circ} \mathbf{C}$ & $\mathbf{p H}$ \\
\hline Day 1 & 7866 & 76.96 & 0.326 & 109 & $3.5 \times 10^{6}$ & 27 & 7.85 \\
\hline Day 2 & 6147.5 & 82.27 & 0.404 & 120 & $6 \times 10^{5}$ & 28.3 & 8.11 \\
\hline Day 3 & 8090 & 80.69 & 0.542 & 123 & $1.4 \times 10^{6}$ & 27.2 & 8.09 \\
\hline Day 4 & 7935 & 78.91 & 0.612 & 124.5 & $2.5 \times 10^{6}$ & 27.1 & 7.95 \\
\hline Day 5 & 5307.5 & 68.16 & 0.722 & 123.5 & $4.5 \times 10^{6}$ & 27.4 & 8.01 \\
\hline
\end{tabular}

There can be observed a high solid content of MLSS in aeration reactor that caused a high sludge volume index. Generally, a higher SVI (> 150) results in the growth of filamentous bacteria with negative effects on biological wastewater treatment performances. However, the number of aerobic mesophilic bacteria in aeration tank is at a certain level to enhance the degradation process of the organic impurities from wastewater. In Figure 3 is presented the evolution of activated sludge activity expressed as $\mu \mathrm{g}$ formazan/mg MLSS versus the number of live cells from aeration basin.
The results obtained emphasize a good correlation between these two parameters, as the number of viable cells is higher the viability and activity of activated sludge (dehydrogenase activity) is improved.

In this respect, the dehydrogenase activity test is able to quantify the number of live cells that are present in the aeration reactor, and it can be used in a relatively short time comparing with counting cells method.

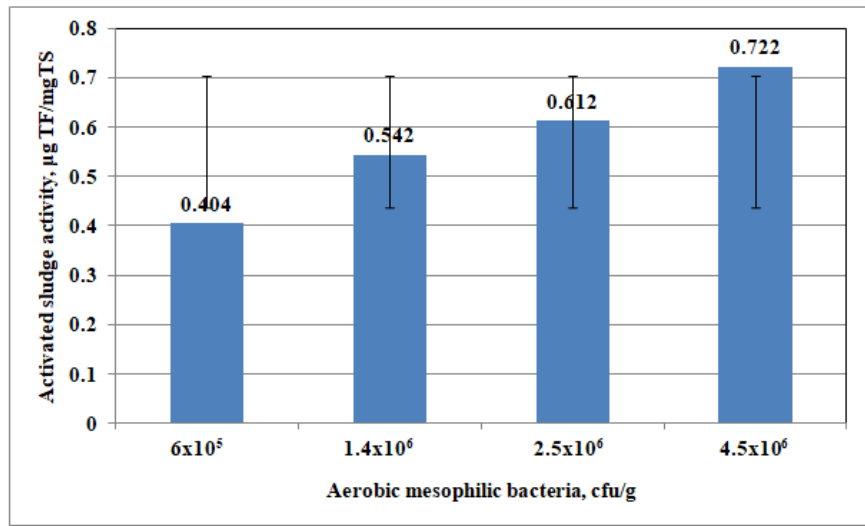

Fig. 3. The correlation between activated sludge activity and aerobic mesophilic bacteria from aeration tank 
During the study period, the volatile suspended solids were between $68.16 \%$ and $82.27 \%$ that involve a good activity of microorganisms in aeration tank. As is presented in Figure 4, between the volatile suspended solids and sludge activity expressed as extracted tryphenil formazan there is no linear correlation. This can be explained by the fact that the active fraction from volatile suspended solids is influenced by the sludge age (as the age of activated sludge is higher the fraction of inert and no biodegradable intra and extra cellular polymers is higher). In this case the high content of TSS of mixed liquor from aeration reactor confirm the high activated sludge age.

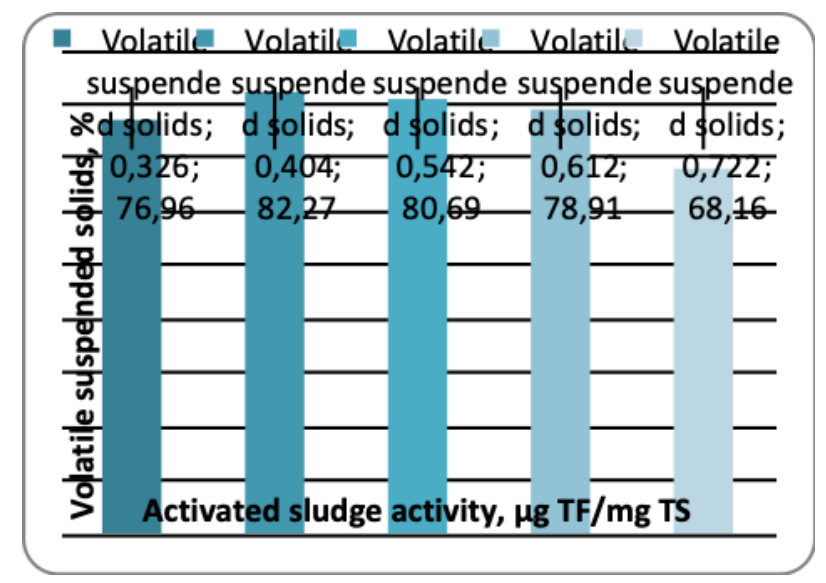

Fig. 4. The correlation between sludge activity and volatile suspended solids

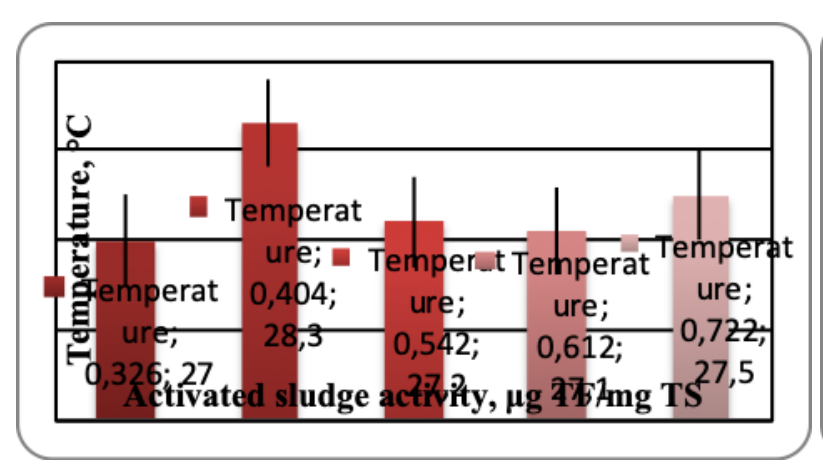

a)

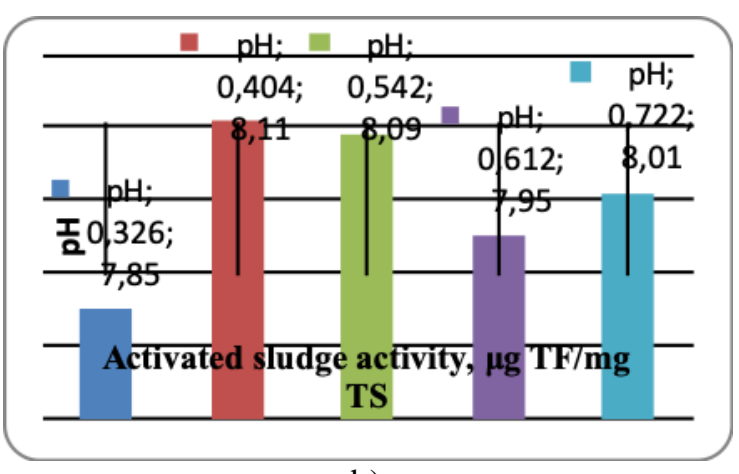

b)

Fig. 5. The influence of temperature (a) and $\mathrm{pH}(\mathrm{b})$ on the activated sludge activity

For most bacteria, the optimal $\mathrm{pH}$ range for growth is 6.5-7.5. The $\mathrm{pH}$ of mixed liquor from aeration tank was between 7.85 and 8.11 as is presented in Table 1. Based on the results presented in Table 1 and Figure 5(b) the activated sludge activity is not influenced by the medium $\mathrm{pH}$ as well as its temperature. The temperature in aeration tank had a lower variation $\left(27{ }^{\circ} \mathrm{C}\right.$ and $\left.28.3{ }^{\circ} \mathrm{C}\right)$ and no influenced the activated sludge activity (Figure 5(a)).

\section{Conclusions}

A dehydrogenase activity measurement test using triphenyl tetrazolium chloride (TTC) was successfully developed and tested to evaluate the activity and viability of microorganisms involved in the biological treatment of wastewaters generated from paper manufacturing process. The obtained results using this method were compared with physical-chemical parameters of biological treatment process. The results showed that TTC method is well suited for measurements of microbial activity in activated sludge.

The analysis of the activated sludge activity based on cells counting or measuring of volatile suspended solids are good indicators and gives useful information regarding the live cell viability, but are time-consuming. Based on the obtained results and good correlation between the activated sludge activity measured using in situ method based on the tetrazolium salt TTC, for the routine measurements this test can be used with good results, giving the information about the live cells after $30 \mathrm{~min}$ (by red colour appearance after the activated sludge is mixed 
with TTC). Furthermore, the TTC method constitutes a convenient and rapid approach for quantification and monitoring of inhibitory effects in activated sludge treatment processes.

\section{Acknowledgement}

This work was supported by a grant of the Romanian National Authority for Scientific Research and Innovation, CNCS/CCCDI-UEFISCDI, project number PN-III-P2-2.1-BG-2016-0040, contract no. $86 \mathrm{BG} / 2016$.

\section{References}

[1]. Sevimli M. F., Post-treatment of pulp and paper industry wastewater by advanced oxidation processes, Ozone: Science and Engineering 27, p. 37-43, 2005.

[2]. Ali M., Sreekrishnan T. R., Aquatic toxicity from pulp and paper mill effluents: a review, Adv Environ Res 5, p. 175-196, 2001.

[3]. Mathur R. M., Panwar S., Gupta M. K., Endlay N., Kukarni A. G., Agro-based pulp and paper mills: environmental status, issues and challenges and the role of Central Pulp and Paper Research Institute, Tewari PK (eds) Liquid asset, proceedings of the Indo-EU workshop on promoting Efficient
Water Use in Agro Based Industries. TERI Press, New Delhi, India, p. 99-114, 2004.

[4]. Kumar V., Dhall P., Naithani S., Kumar A., Kumar R., Biological Approach for the Treatment of Pulp and Paper Industry Effluent in Sequence Batch Reactor, J Bioremed Biodeg, 5(3), http://dx.doi.org/10.4172/2155-6199.1000218, 2014.

[5]. Al-Shahwani S. M., Horan N. J., The use of protozoa to indicate changes in the performance of activated sludge plants, WaterRes., 25, p. 633-638, 1991.

[6]. Madoni P., Role of protozoans and their indicator value in the activated sludge process, Madoni $\mathrm{P}$, (ed.) Biological Approach to Sewage Treatment Process: Current Status and Perspectives. Centro Bazzucchi, Perugia, Italy, p. 21-27, 1991.

[7]. Griebe T., Schaule G., Wuertz S., Determination of microbial respiratory and redox activity in activated sludge, Journal of Industrial Microbiology \& Biotechnology, 19, p. 118$122,1997$.

[8]. Madoni P., A sludge biotic index (SBI) for the evaluation of the biological performance of activated sludge plants based on the microfauna analysis, Water Research, 28, p. 67-75,1994.

[9]. Backor M., Fahselt D., Tetrazolium reduction as an indicator of environmental stress in lichens and isolated bionts, Environ Exper Bot, 53, p. 125-133, 2005.

[10]. Burdock T. J., Brooks M. S., Ghaly A. E., A dehydrogenase activity test for monitoring the growth of streptomyces venezuelae in a nutrient rich medium, J Bioproces Biotechniq, 1(1), p. 1-10, http://dx.doi.org/10.4172/2155-9821.1000101, 2011.

[11]. Zhao X., Li H., Wu Q., Li Y., Zhao C., et al., Analysis of dehydrogenase activity in phytoremediation of composite pollution sediment, $2^{\text {nd }}$ Conference on Environmental Science and Information Application Technology, 2010. 